\title{
Optimal monetary policy in a model of vertical production and trade with reference currency
}

\author{
${ }^{1}$ Peking University, Guanghua School of Management and LMEQF, Beijing, China \\ ${ }^{2}$ Central University of Finance and Economics, School of Finance, Beijing, China, E-mail: wangchanist@126.com \\ ${ }^{3}$ Central University of Finance and Economics, China Economics and Management Academy, Beijing, China
}

\begin{abstract}
:
This paper examines optimal monetary policy rules in a model of vertical production and trade with reference currency. As evidenced by empirical findings, we assume that final-goods prices are sticky, but intermediategoods prices are flexible. We find that even if intermediate-goods prices are flexible, monetary authorities need to respond to the shocks at the stage of intermediate-goods production. We also find that, when a shock occurs at the stage of final-goods production, monetary responses are independent of the expenditure share of finalgoods producers on intermediate goods. For the first time in the literature, our model gives a condition under which both countries are willing to participate in monetary cooperation. Thus the gains from cooperation are real. In addition, we compare the volatility of the nominal exchange rate in Nash case with that in cooperative case, and compare the volatility of the nominal exchange rate in our model with that in a model without vertical production and trade as well. We also extend the model to consider a case of dual price stickiness. We find that the change in solution methods completely alters the conclusions of the model.
\end{abstract}

Keywords: exchange rates, monetary cooperation, optimal monetary policy, reference-currency pricing, vertical production and trade

JEL classification: E5, F3, F4

DOI: $10.1515 /$ bejm-2014-0148

\section{Introduction}

Currently, global economy is increasingly integrated by vertical production and trade processes, more and more countries are trading not only consumption goods but also a large quantity of intermediate inputs. Using inputoutput tables from 10 OECD and four emerging market countries, Hummels, Jun, and Yi (2001) find that vertical specialization accounts for $21 \%$ of these countries' export, and grows almost $30 \%$ from 1970 to 1990 . In addition, Feenstra (1998), Hummels, Dana, and Yi (1998), and Yi (2003, 2010), and Bridgman (2012) also emphasize the importance of vertical production and trade in the development of world economy.

Another important empirical fact is that US dollar plays a dominant role in the international trade, however, academic researchers have paid scant attention to it. Using quarterly data of 23 OECD countries from 1975 to 2003, Campa and Goldberg (2005) provide cross-country and time-series evidence on pass-through into the import prices. They find that US has the lowest pass-through rate among the OECD countries. Gopinath, Itskhoki, and Rigobon (2010) show that the exchange rate pass-through of the average good priced in dollars is much lower than that priced in nondollars. Goldberg and Tille (2008 and 2009) provide the empirical evidence which clearly highlights the global role of the dollar. They find that dollar is used in the invoicing of trade not only between US and its trading partners but also among trading partners except for US. Shi and Xu (2010), hereafter SX, study the problem of twin dollarization which is motivated by the observation in East Asian economies, which not only borrow bonds denominated in US dollar but also price their export goods in US dollar. In terms of Devereux, Shi, and Xu (2007), hereafter DSX, US dollar plays the role of reference currency with which both home and foreign exporters set prices.

How does the vertical production and trade with reference currency shape optimal monetary policies? In order to answer this question, we introduce reference currency into a model of vertical production and trade similar to SX (2007). In addition, following Devereux and Engel (2007), hereafter DE, we assume that final-goods prices are sticky, but intermediate-goods prices are flexible, which is supported by vast of empirical literature. ${ }^{1}$ In order to make the model general enough, we also assume home bias both in consumption and production.

Our research follows the tradition initiated by Feldstein (1992), Friedman (1953), and Mundell (1961) who believe that, when nominal goods prices are sticky, freely floating exchange rates can achieve relative price 
adjustment between countries. The reason is that flexible exchange rates can deal with real country-specific productivity or demand shocks. More recently, by combining intertemporal choice and nominal rigidities, Obstfeld and Rogoff (2000), hereafter OR, propose a framework to analyze optimal monetary policy rules in open economies, and conclude that a global monetary policy that replicates the allocations under flexible wages is efficient. OR (2002) generalize OR (2000) to the case with incomplete international asset markets. If the shocks are global, optimal monetary policy rules involve replicating the allocations under flexible wages, furthermore, there are no gains from cooperation. By comparison, if shocks are country specific, optimal monetary policy rules cannot replicate the allocations under flexible wages, and gains from cooperation, though quantitatively small, can emerge. However, OR's conclusions are based on the assumption that exporters set prices in the currency of the producers (PCP). DE (2003) not only consider the PCP case but also the situation in which exporters set prices in consumers' currency (LCP). In PCP case, optimal monetary policy rules can replicate flexible-price allocations, and flexible exchange rate is optimal. Comparatively, in LCP case, optimal monetary policy rules can not replicate flexible-price allocations and fixed exchange rate is optimal. Building on DE (2003), DSX (2007) analyze the case in which both home and foreign exporters set prices in reference currency (denoted as reference currency pricing or RCP). They find that there are no gains from monetary cooperation and in a Nash equilibrium, a home representative household's expected utility level is always lower than that of her foreign counterpart. SX (2007) explore optimal monetary policy in a model of vertical production and trade, they find a productivity shock in a country can cause a trans-border spillover effect thus both home and foreign monetary authority need to respond to it. Furthermore, they find that the volatility of the nominal exchange rate is lower after vertical production and trade is introduced. Wang and Zou (2015) examine optimal monetary policy in a model of vertical production and trade with reference currency, and find home household's expected utility level is not always lower than that of her foreign counterpart. The outcome depends on the comparison of relative expenditure share on consumption with that on production.

In general, monetary policy does not need to respond to a productivity shock when the prices are flexible. Relative price can adjust freely to achieve efficiency. By comparison, in our model of vertical production and trade with reference currency, even if prices at the intermediate-goods (lower) stage of the production are flexible, due to price stickiness at the final-goods (upper) stage of the production, monetary policy needs to respond to the productivity shocks at the lower stage of the production. Specifically, if there is a positive productivity shock at the home lower stage of the production and monetary authorities take no action, it is certain that home and foreign prices of home intermediate goods will go down due to a lower marginal cost. Consequently, home and foreign final-goods producers will increase the input of home intermediate goods due to the normal substitution and income effects, but they will reduce the input of foreign intermediate goods since home and foreign final-goods outputs keep unchanged. Thus, it means an adverse shock to foreign intermediate-goods firms. In this circumstance, foreign monetary authority depreciates its currency to boost the demands for its own country's intermediate goods. However, the depreciation will depress the demands for home intermediate goods and also lower foreign demand for home final goods. In order to counterbalance the adverse effects, home monetary authority also expands money supply. In addition, we also find that, when a shock occurs at the upper stage of the production, monetary responses are independent of the expenditure share of final-goods producers on intermediate goods.

A classical question in the open economy macroeconomics literature is whether there are gains from monetary cooperation between monetary authorities. Though some researchers find that there are no gains from monetary cooperation, ${ }^{2}$ some find there are gains indeed. ${ }^{3}$ However, all researchers ignore a realistic question, i.e. are all the involving countries willing to participate in the cooperation? After taking part in monetary cooperation, If the utility levels of the households in both countries are greater than playing a Nash game, then the gains from monetary cooperation are real, otherwise, the gains are false.

In the literature, for the first time, our model produces real gains from monetary cooperation. To be specific, if the covariance between productivity shocks at the two stages is greater than zero, furthermore, if the covariance is greater than a proportion of the variance, then the gains from cooperation are real. By comparison, if we do not consider vertical production and trade, pure reference currency pricing leads to different policy effectiveness for home and foreign monetary authorities, and gains from monetary cooperation will emerge but they are false.

Does monetary cooperation result in less volatile nominal exchange rates? The problem is discussed in OR (2002), and the answer depends on the coefficient of relative risk aversion. In our model, when the coefficient of relative risk aversion is exactly unity, the answer depends on the covariance of the productivity shocks at both stages of the production and home bias in production. When the covariance is equal to zero, our conclusion is the same as that without vertical production and trade. If there is no vertical production and trade, in RCP case, the expenditure-switching effect only works in foreign markets. When monetary policy rules are chosen cooperatively, the monetary policy maker will make better use of the expenditure-switching effect to improve the welfare levels of households in both countries. Consequently, a more volatile exchange rate is needed. When 
there is no home bias in production, monetary responses to productivity shocks at the lower stage of the production do not affect the volatility of the nominal exchange rates in both Nash and cooperative cases. Therefore, the conclusion obtained in the case of no vertical production and trade still holds. When the covariance is strictly greater than zero and final-goods producers bias towards domestic intermediate goods, or the covariance is strictly less than zero and final-goods producers bias towards imported intermediate goods, the introduction of vertical production and trade will make the nominal exchange rates in both Nash and cooperative cases more volatile but does not change the ordering between them. When the covariance is strictly less than zero and finalgoods producers bias towards domestic intermediate goods, or the covariance is strictly greater than zero and final-goods producers bias towards imported intermediate goods, two outcomes arise. Intuitively, after vertical production and trade is introduced, flexible prices at the lower stage of the production permit full exchange-rate pass-through. After a positive productivity shock occurs at the home lower stage of the production, it tends to lower home intermediate-goods prices facing a foreign final-goods producer through the channel of marginal cost. Meanwhile, an expansionary response of home monetary authority will further lower home intermediategoods prices facing a foreign final-goods producer through the channel of the nominal exchange rate. These two effects operate in the same direction and affect the foreign adversely. When monetary policy rules are chosen cooperatively, the monetary policy maker will avoid an excessively volatile exchange rate at the lower stage of the production. Thus, when choosing monetary policy rules cooperatively, the monetary policy maker faces a trade-off. For one thing, she wants a more volatile exchange rate at the upper stage of the production to take advantage of the one-sided expenditure-switching effect. For another, she wants a less volatile exchange rate at the lower stage of the production to avoid the negative externality of the monetary policy. Thus in one case, the desire to avoid a more volatile exchange rate at the lower stage of the production dominates thus the volatility of the nominal exchange rate in cooperative case is less than or equal to that in Nash case; in another case, the desire to have a more volatile exchange rate at the upper stage of the production dominates thus the volatility of the nominal exchange rate in cooperative case is greater than that in Nash case.

SX (2007) find that, in PCP case, after vertical production and trade is introduced into an otherwise standard sticky-price model, the nominal exchange rate becomes more stable. After we introduce RCP and assume flexible prices at the lower stage of the production, the nominal exchange rate does not always become more stable when there is vertical production and trade. Intuitively, when there is an additional shock to deal with which does not interact with the existing shocks, under the condition that monetary responses to the new shock does not affect those to the existing shocks, monetary responses to the new shock will cause the nominal exchange rate more volatile. In this case, we call the greater volatility comes from the dimension effect of the monetary policy. In our model, the dimension effect always magnifies the volatility of the nominal exchange rate. In addition, the interaction between the shock at the upper stage and that at the lower stage produces an interaction effect. The direction of the interaction effect depends on the covariance and home bias in production. In SX (2007), the authors only consider a special case in which there is no home bias both in consumption and production. Thus the dimension effect does not magnify the volatility of the nominal exchange rate, on the contrary, it lowers the volatility. When the covariance is strictly greater than zero, the interaction effect can increase the volatility, but the increase falls short of the decrease from the dimension effect. As a result, the exchange rate is less volatile after vertical production and trade is introduced.

We also extend the model to consider the case of dual price stickiness. In this case, we can not obtain model's closed-form solution and have to approximate the equilibrium system up to a first order and the welfare function up to a second order. Thus monetary authorities need to focus on the deviation of employment from its steady state not the expected consumption as before. As a result, monetary authorities can achieve the utility levels in flexible-price equilibrium which are identical in both countries. Thus, the gains from monetary cooperation disappear.

The paper is organized as follows. Section 2 presents the benchmark model and solves for a flexible price equilibrium. Section 3 analyzes optimal monetary policy rules and their implications. Section 4 extends the benchmark model to consider dual price stickiness. Section 5 concludes.

\section{The benchmark model}

We consider a static, two-country model with vertical production and trade. The model's structure is similar to that of SX (2007), but as DSX (2007), we introduce asymmetry in the pricing behavior of exporters in home and foreign country in the sense that home exporters set prices in the currency of the producers (PCP), foreign exporters, however, set prices in the currency of the consumers (LCP). In terms of DSX (2007), home currency is the reference currency. In the following, we call the pricing scheme in which home and foreign exporters set prices in terms of reference currency as reference currency pricing (RCP). In the benchmark model, we follow 
a large empirical literature and assume sticky prices at the stage of final-goods production but flexible prices at the stage of intermediate-goods production. As a comparison, in the extension of the benchmark model, we consider the case which involves price stickiness at both stages of the production.

The two countries, home and foreign, are both populated by a continuum of households of measure 1 . The production sectors, both in home and foreign, are separated into two stages, one uses both home and foreign intermediate goods to produce the final goods which are then consumed by households in the world; the other uses only domestic labor to produce the intermediate goods.

There is only a single period which is divided into two sub-periods by productivity shocks. In the first sub-period, households trade in a full set of state-contingent bonds denominated in the home currency, then monetary authorities announce monetary policy rules to the public, sticky-price firms set prices. In the second sub-period, flexible-price firms set prices, production inputs are employed, outputs are produced, households supply labor and choose consumption, and the exchange rate is determined. Throughout the period, we assume that monetary authorities are able to commit to monetary policy rules.

In the following, asterisks denote foreign variables, lower-case letter $f$ denotes the final good, $i$ the intermediate goods.

\subsection{Households}

The expected utility of a home representative household $h \in[0,1]$ is given by

$$
U(h)=E\left[\ln C(h)+\chi \ln \frac{M(h)}{P}-\eta L(h)\right],
$$

in which $\frac{M(h)}{P}$ is the real money balances, $L(h)$ is the labor supply, $\chi$ and $\eta$ are positive constants, and real consumption index $C(h)$ has an Armington form,

$$
C(h)=\frac{C_{H}^{n}(h) C_{F}^{1-n}(h)}{n^{n}(1-n)^{1-n}},
$$

in which $n$ is the expenditure share of the home household on home final-goods subindex, in addition, $n$ also describes the degree of home bias in consumption. Consumption subindexes $C_{H}(h)$ and $C_{F}(h)$ are defined respectively by

$$
C_{H}(h)=\left[\int_{0}^{1} C_{H}\left(h, j_{f}\right)^{\frac{\lambda-1}{\lambda}} d j_{f}\right]^{\frac{\lambda}{\lambda-1}}, C_{F}(h)=\left[\int_{0}^{1} C_{F}\left(h, j_{f}^{*}\right)^{\frac{\lambda-1}{\lambda}} d j_{f}^{*}\right]^{\frac{\lambda}{\lambda-1}},
$$

where $\lambda>1$ is the elasticity of substitution between final goods, ${ }^{4} j_{f} \in[0,1]$ denotes home final good $j, j_{f}^{*} \in[0,1]$ denotes foreign final good $j^{*}$.

Home price index for overall real consumption index $C(h)$ is

$$
P=\left(P_{H H f}\right)^{n}\left(P_{F H f}\right)^{1-n},
$$

in which $P_{H H f}\left(P_{F H f}\right)$ denotes price subindex for home (foreign) final goods sold in the home country. Household $h^{\prime} s$ demands for $j_{f}$ and $j_{f}^{*}$ are respectively:

$$
\begin{aligned}
& C_{H}\left(h, j_{f}\right)=n\left[\frac{P_{H H f}\left(j_{f}\right)}{P_{H H f}}\right]^{-\lambda}\left[\frac{P_{H H f}}{P}\right]^{-1} C(h), \\
& C_{F}\left(h, j_{f}^{*}\right)=(1-n)\left[\frac{P_{F H f}\left(j_{f}^{*}\right)}{P_{F H f}}\right]^{-\lambda}\left[\frac{P_{F H f}}{P}\right]^{-1} C(h) .
\end{aligned}
$$

Due to asymmetry in pricing behavior of the exporters in home and foreign, foreign price index is

$$
P^{*}=\left(\frac{P_{H F f}}{S}\right)^{1-n}\left(P_{F F f}^{*}\right)^{n}
$$


in which $P_{H F f}\left(P_{F F f}^{*}\right)$ denotes price subindex for home (foreign) final goods sold in foreign, $S$ is the nominal exchange rate representing the home currency price of one unit of foreign currency.

Household $h$ maximizes her expected utility subject to the following budget constraint,

$$
P(z) C(h, z)+M(h, z)+\sum_{z^{\prime} \in Z} q\left(z^{\prime}\right) B\left(h, z^{\prime}\right)=W(z) L(h, z)+\Pi(h, z)+B(h, z)+M_{0}+T(h, z),
$$

where $z \in Z$ represents a particular natural state, and $Z$ is the set of all states. $B\left(h, z^{\prime}\right)$ is the amount of bonds held by household $h$ which entitles her to be paid $B$ units of home currency when state $z^{\prime}$ occurs, and $q\left(z^{\prime}\right)$ is the home currency price of the state-contingent bond, $W(z) L(h, z)$ is nominal wage income, $\Pi(h, z)$ represents profits from the ownership of home firms which distribute their profits among domestic households equally; $T(h, z)$ is lump-sum transfer from home government which rebates it's seigniorage revenue to home households equally, it means $M(z)-M_{0}=T(z) ; M_{0}$ is initial holdings of nominal money balances.

We can solve home household $h$ 's time-0 problem and obtain the following first-order conditions:

$$
M(h, z)=\chi P(z) C(h, z), W(z)=\eta P(z) C(h, z) .
$$

The above two equations are intratemporal optimization conditions to ensure that marginal utilities from holding an extra unit of money or enjoying one additional unit of leisure are equal to marginal costs measured by forgone consumption respectively.

In addition, risk sharing between home and foreign households will equalize their marginal utilities from holding one unit of nominal state-contingent bond, it means that the following risk-sharing condition holds:

$$
\Gamma P(z) C(h, z)=S(z) P^{*}(z) C^{*}\left(h^{*}, z\right) \text { for any } h \text { and } h^{*},
$$

in which $\Gamma$ is the ratio of home and foreign households' Lagrange multipliers and is determined by an equilibrium condition in the market for state-contingent nominal bonds. As shown in the Appendix of DE (2003), $\Gamma$ $=1$ holds when log utility function of consumption is assumed. However, it is noteworthy that, in general, $\Gamma$ differs from 1 to reflect the difference between home and foreign which is caused by asymmetry in the pricing behavior of the exporters in home and foreign. ${ }^{5}$

In a symmetric equilibrium, the optimization conditions and the risk-sharing condition can be written as:

$$
\begin{gathered}
M=\chi P C \\
W=\eta P C \\
P C=S P^{*} C^{*}
\end{gathered}
$$

\subsection{Firms}

Home final goods are produced by a continuum of firms indexed by $j_{f} \in[0,1]$ with production function,

$$
Y_{H f}\left(j_{f}\right)=\frac{\theta_{f} Y_{H i}\left(j_{f}\right)^{\varepsilon} Y_{F i}\left(j_{f}\right)^{1-\varepsilon}}{\varepsilon^{\varepsilon}(1-\varepsilon)^{1-\varepsilon}},
$$

in which $\theta_{f}$ is a home productivity shock at the stage of final-goods production, $\varepsilon$ is the expenditure share of the firm $j_{f} \in[0,1]$ on home intermediate-goods aggregator, in addition, $\varepsilon$ also denotes home bias in production. $Y_{H i}\left(j_{f}\right)\left(Y_{F i}\left(j_{f}\right)\right)$ is an index which bundles differentiated home (foreign) intermediate goods together and given by, 


$$
\begin{aligned}
& Y_{H i}\left(j_{f}\right)=\left[\int_{0}^{1} Y_{H i}\left(j_{f}, j_{i}\right)^{\frac{\phi-1}{\phi}} d j_{i}\right]^{\frac{\phi}{\phi-1}}, \phi>1 \\
& \left(Y_{F i}\left(j_{f}\right)=\left[\int_{0}^{1} Y_{F i}\left(j_{f}, j_{i}^{*}\right)^{\frac{\phi-1}{\phi}} d j_{i}^{*}\right]^{\frac{\phi}{\phi-1}}, \phi>1 .\right)
\end{aligned}
$$

The unit cost function of a home representative firm $j_{f} \in[0,1]$ is $C\left(P_{H H i}, P_{F H i}\right)=\frac{P_{H H i}^{\varepsilon} P_{F H i}^{1-\varepsilon}}{\theta_{f}}$. The expressions for $Y_{H i}\left(j_{f}\right)$ and $Y_{F i}\left(j_{f}\right)$ imply that the demands for home and foreign intermediate goods by a home final-good firm $j_{f}$ are respectively,

$$
Y_{H i}\left(j_{f}, j_{i}\right)=\varepsilon\left(\frac{P_{H H i}\left(j_{i}\right)}{P_{H H i}}\right)^{-\phi}\left(\frac{P_{H H i}}{C\left(P_{H H i}, P_{F H i}\right)}\right)^{-1} Y_{H f}\left(j_{f}\right)
$$

and

$$
Y_{F i}\left(j_{f}, j_{i}^{*}\right)=(1-\varepsilon)\left(\frac{P_{F H i}\left(j_{i}^{*}\right)}{P_{F H i}}\right)^{-\phi}\left(\frac{P_{F H i}}{C\left(P_{H H i}, P_{F H i}\right)}\right)^{-1} Y_{H f}\left(j_{f}\right) .
$$

At the lower stage of the production, differentiated intermediate goods are produced by a continuum of firms indexed by $j_{i} \in[0,1]$ with production function

$$
Y_{H i}\left(j_{i}\right)=\theta_{i} L\left(j_{i}\right),
$$

where $\theta_{i}$ is a home productivity shock at the lower stage of the production, $L\left(j_{i}\right)$ is firm $j_{i}^{\prime} s$ demand for domestic labor.

Following SX (2007), we assume that $\theta_{f}=\exp (u)$ and $\theta_{i}=\exp (v)$, in which $u$ and $v$ are normally distributed with zero mean and variance-covariance matrix

$$
\sum=\left(\begin{array}{cc}
\sigma_{u}^{2} & \sigma_{u v} \\
\sigma_{u v} & \sigma_{v}^{2}
\end{array}\right) .
$$

Foreign productivity shocks are also assumed to have the above properties. To keep calculations as simply as possible, we assume $\sigma_{u}^{2}=\sigma_{v}^{2}=\sigma_{u^{*}}^{2}=\sigma_{v^{*}}^{2}=\sigma^{2}, \sigma_{u v}=\sigma_{u^{*} v^{*}}$ and $\sigma_{u u^{*}}=\sigma_{u v^{*}}=\sigma_{u^{*} u}=\sigma_{u^{*} v}=0$. Thus, $-\sigma^{2} \leq \sigma_{u v} \leq \sigma^{2}$ follows.

Note that our model is flexible enough to permit us to discuss the case in which vertical production and trade is absent, which corresponds to $\varepsilon=1, \theta_{i}=\theta_{i}^{*}=1$.

\subsection{The flexible-price equilibrium}

We first solve flexible-price equilibrium. When prices are flexible at both stages of production, all firms set prices after shocks are realized. The solutions for optimal pricing choices are given in Table 1. A representative firm will set its price on the basis of marginal cost adjusted by the markup to reflect its market power. Since foreign exporters set prices in the currency of the home consumers, their prices in the home country are adjusted by the nominal exchange rate.

Table 1: Optimal prices when they are flexible.
$P_{H H f}=\frac{\lambda}{\lambda-1} \frac{P_{H H i}^{\varepsilon} P_{F H i}^{1-\varepsilon}}{\theta_{f}}$
$P_{H F f}=\frac{\lambda}{\lambda-1} \frac{P_{H H i}^{e} i_{F H i}^{1-\varepsilon}}{\theta_{f}}$
$P_{F H f}=\frac{\lambda}{\lambda-1} \frac{S\left(\frac{P_{H F i}}{S}\right)^{1-\varepsilon}\left(P_{F F i}^{*}\right)^{\varepsilon}}{\theta_{f}^{*}}$
$P_{H H i}=\frac{\phi}{\phi-1} \frac{W}{\theta_{i}}$
$P_{F H i}=\frac{\phi}{\phi-1} \frac{W^{*}}{\theta_{i}^{*}} S$

$$
\begin{aligned}
& P_{F F f}^{*}=\frac{\lambda}{\lambda-1} \frac{\left(\frac{P_{H F i}}{S}\right)^{1-\varepsilon}\left(P_{F F i}^{*}\right)^{\varepsilon}}{\theta_{f}^{*}} \\
& P_{H F i}=\frac{\phi}{\phi-1} \frac{W}{\theta_{i}} \\
& P_{F F i}^{*}=\frac{\phi}{\phi-1} \frac{W^{*}}{\theta_{i}^{*}}
\end{aligned}
$$


Market clearing condition in the home country can be written as

$$
\begin{aligned}
\theta_{i} L= & \varepsilon \frac{C\left(P_{H H i}, P_{F H i}\right)}{P_{H H i}}\left(n \frac{P C}{P_{H H f}}+(1-n) \frac{S P^{*} C^{*}}{P_{H F f}}\right) \\
& +(1-\varepsilon) \frac{S C^{*}\left(\frac{P_{H F i}}{S}, P_{F F i}^{*}\right)}{P_{H F i}}\left((1-n) \frac{P C}{P_{F H f}}+n \frac{P^{*} C^{*}}{P_{F F f}^{*}}\right) .
\end{aligned}
$$

The first term on the right-hand side of the previous equation is the demands for home intermediate goods of home final-goods firms, the second term is the demands for home intermediate goods of foreign final-goods producers.

Since $M$ and $M^{*}$ are chosen by monetary authorities in home and foreign, $\theta_{f}, \theta_{f}^{*}, \theta_{i}, \theta_{i}^{*}$ are exogenous productivity shocks, flexible price equilibrium consists of 17 equations: 8 pricing equations in Table 1, home price index (1) and its foreign equivalent (2), money demand equation (3) and its foreign equivalent, labor supply equation (4) and its foreign equivalent, risk sharing condition (5), market clearing condition (6) and its foreign equivalent. From these 17 equations, 17 endogenous variables $P_{H H f}, P_{H F f}, P_{F H f}, P_{F F f}^{*}, P_{H H i}, P_{H F i}, P_{F H i}, P_{F F i}^{*}, S, W, W^{*}, P, P^{*}, C, C^{*}, L, L^{*}$ can be determined. In the following, a variable with a tilde represents its flexible-price counterpart.

Solving flexible price equilibrium system yields

$$
\widetilde{\tau_{i}}=\frac{\theta_{i}}{\theta_{i}^{*}}
$$

in which $\widetilde{\tau_{i}}$ is home terms of trade at the lower stage of the production. Equation (7) implies that a home positive productivity shock at the lower stage of the production will deteriorate home terms of trade of the stage.

Similarly, home terms of trade at the upper stage of the production is

$$
\widetilde{\tau_{f}}=\frac{\theta_{f}}{\theta_{f}^{*}}\left(\frac{\theta_{i}}{\theta_{i}^{*}}\right)^{2 \varepsilon-1}
$$

From equation (8), besides productivity shocks at the upper stage of the production, the productivity shocks at the lower stage of the production also affect home terms of trade at the upper stage of the production except for the special case of no home bias in production. Specifically, if final-goods firms exhibit home bias in the production $(\varepsilon>1 / 2)$, a home positive productivity shock at the lower stage of the production will also deteriorate home terms of trade of the upper stage of the production. Otherwise, it will improve home terms of trade of the upper stage of the production.

The nominal exchange rate depends on relative nominal money balances and is given by

$$
\tilde{S}=\frac{\widetilde{M}}{\widetilde{M^{*}}}=\frac{\widetilde{W}}{\widetilde{W^{*}}} .
$$

Equation (9) implies that, if home central bank issues more money than its foreign counterpart, home currency will depreciate.

With home bias being in place both in consumption and production, consumption is no longer identical between home and foreign, home consumption is given by

$$
\widetilde{C}=\left(\eta \lambda_{m} \phi_{m}\right)^{-1} \theta_{f}^{n} \theta_{f}^{*^{1-n}} \theta_{i}^{\varepsilon n+(1-\varepsilon)(1-n)} \theta_{i}^{*^{n(1-\varepsilon)+\varepsilon(1-n)}},
$$

in which $\lambda_{m} \equiv \frac{\lambda}{\lambda-1}$ is the final-goods producers' markup, $\phi_{m}$ is defined similarly. From equation (10), consumption depends on a geometric weighted average of global productivity shocks. As a comparison, foreign consumption is given by $\widetilde{C^{*}}=\left(\eta \lambda_{m} \phi_{m}\right)^{-1} \theta_{f}^{1-n} \theta_{f}^{*^{n}} \theta_{i}^{n(1-\varepsilon)+\varepsilon(1-n)} \theta_{i}^{*^{\varepsilon n+(1-\varepsilon)(1-n)}}$. Unlike consumption, employment is the same between home and foreign and has the form

$$
\tilde{L}=\widetilde{L^{*}}=\frac{1}{\eta \lambda_{m} \phi_{m}} .
$$


It is noteworthy that the employment under flexible prices is not affected by global productivity shocks, the conclusion doesn't hold when we consider a general CRRA utility function of consumption.

Home bias in consumption implies that PPP does not hold and the real exchange rate is

$$
\widetilde{R}=\frac{\widetilde{S} \widetilde{P^{*}}}{\widetilde{P}}=\left(\frac{\theta_{f}^{*}}{\theta_{f}}\right)^{1-2 n}\left(\frac{\theta_{i}}{\theta_{i}^{*}}\right)^{(1-2 n)(1-2 \varepsilon)} .
$$

Following the convention initiated by OR $(1995,2001,2000$, and 2002) we focus on the "real" component of a representative household's utility and assume $\chi \rightarrow 0$. Thus, expected utility under flexible prices is given by

$$
E \widetilde{U}=E \widetilde{U^{*}}=-\ln \left(\eta \lambda_{m} \phi_{m}\right)-\frac{1}{\lambda_{m} \phi_{m}},
$$

in which $-\ln \left(\eta \lambda_{m} \phi_{m}\right)$ is the expected utility from consumption and $-\frac{1}{\lambda_{m} \phi_{m}}$ from labor supply.

\section{Optimal monetary policy rules}

Now, we consider optimal monetary policy rules in the case in which final-goods prices are sticky, but intermediate-goods prices are flexible. The case is supported by US data. Among many others, Murphy, Shleifer, and Vishny (1989) and Clark (1999) find that final-goods prices are significantly less volatile than intermediate goods; Bils and Klenow (2004) estimate that price flexibility of "raw goods" is about 3-4 times than that of processed goods; Nakamura and Steinsson (2008) also find that final-goods prices are less volatile than that of intermediate goods.

We assume that monetary authorities can set monetary policy rules with commitment, in the sense that they take account of the effects of their policy rules on households' expected consumption, since their monetary decisions can influence the levels of the pre-set prices. In line with OR (2002), DE (2003), DSX (2007), SX (2007), the optimal monetary policy rules are log-linear functions of global productivity shocks and given by

$$
\begin{aligned}
& m=a_{1} u+a_{2} u^{*}+a_{3} v+a_{4} v^{*}, \\
& m^{*}=b_{1} u+b_{2} u^{*}+b_{3} v+b_{4} v^{*},
\end{aligned}
$$

in which $m=\ln M$. From now on, lower-case letter denotes logarithmic value of a variable.

Clearly, intermediate-goods firms' pricing schemes are the same as those in Table 1, final-goods firms, however, choose prices before the realization of the productivity shocks, and their optimal prices are given in Table 2.

Table 2: Optimal final-goods prices when they are sticky.

$$
\begin{array}{ll}
P_{H H f}=\frac{\lambda}{\lambda-1} E\left(\frac{P_{H H i}^{\varepsilon} P_{F H i}^{1-\varepsilon}}{\theta_{f}}\right) & P_{H F f}=\frac{\lambda}{\lambda-1} E\left(\frac{P_{H H i}^{e} P_{F H i}^{1-\varepsilon}}{\theta_{f}}\right) \\
P_{F H f}=\frac{\lambda}{\lambda-1} E\left(S \frac{\left(\frac{P_{H F i}}{S}\right)^{1-\varepsilon}\left(P_{F F i}^{*}\right)^{\varepsilon}}{\theta_{f}^{*}}\right) & P_{F F f}^{*}=\frac{\lambda}{\lambda-1} E\left(\frac{\left(\frac{P_{H F i}}{S}\right)^{1-\varepsilon}\left(P_{F F i}^{*}\right)^{\varepsilon}}{\theta_{f}^{*}}\right)
\end{array}
$$

Each of the pricing functions in Table 2 is derived from solving the optimization problem facing the finalgoods firms who seek to maximize their expected discounted profits, using the nominal discount factor of their own country's households to discount. We use four pricing functions in Table 2 to replace their respective counterparts in Table 1. These four pricing equations, together with other 13 equations which are the same as their counterparts in flexible-price equilibrium system, form a new equilibrium system.

Now we turn to solve the nominal exchange rate and consumption in the new equilibrium system. From equation (3) and its foreign equivalent, risk-sharing condition (5), we have

$$
s-E s=(m-E m)-\left(m^{*}-E m^{*}\right) .
$$


From equations (1), (3) and using the fact that both $P_{H H f}$ and $P_{F H f}$ are predetermined, we have

$$
c-E c=m-E m .
$$

From equation (2), (3)'s foreign equivalent, (16) and using the fact that $P_{H F f}$ and $P_{F F f}^{*}$ are sticky, we have

$$
c^{*}-E c^{*}=(1-n)(m-E m)+n\left(m^{*}-E m^{*}\right) .
$$

Observing equations (17) and (18), we know that, unlike its foreign analog, home consumption is not affected by foreign monetary policy. The reason is that home CPI is predetermined in RCP case. The same equations are also obtained in DSX (2007). The objective of each monetary authority is to maximize the expected utility of its own country's representative household. Following the literature, we ignore the utility from real balances and solve the expected utility from consumption and employment and express it as a function of parameters chosen by monetary authorities.

Following DSX (2007) and SX (2007), home expected employment is identical to its foreign counterpart and has the form

$$
E L=E L^{*}=\frac{1}{\eta \lambda_{m} \phi_{m}}
$$

Home expected utility from consumption can be expressed as

$$
\begin{aligned}
E c= & -\ln \left(\eta \lambda_{m} \phi_{m}\right)-\frac{\sigma_{c}^{2}}{2}+n \sigma_{c u}+(1-n) \sigma_{c u^{*}}+(n \varepsilon+(1-n)(1-\varepsilon)) \sigma_{c v} \\
& +(n(1-\varepsilon)+\varepsilon(1-n)) \sigma_{c v^{*}}-\frac{n}{2} \sigma_{u}^{2}-\frac{(1-n)}{2} \sigma_{u^{*}}^{2}-n \varepsilon \sigma_{u v}-\varepsilon(1-n) \sigma_{u^{*} v^{*}} \\
& -\left(\frac{n \varepsilon^{2}}{2}+\frac{(1-n)(1-\varepsilon)^{2}}{2}\right) \sigma_{v}^{2}-\left(\frac{n(1-\varepsilon)^{2}}{2}+\frac{(1-n) \varepsilon^{2}}{2}\right) \sigma_{v^{*}}^{2}
\end{aligned}
$$

and its foreign counterpart is

$$
\begin{aligned}
E c^{*}= & -\ln \left(\eta \lambda_{m} \phi_{m}\right)-\frac{\sigma_{c^{*}}^{2}}{2}-\frac{n(1-n)}{2} \sigma_{s}^{2}+n(1-n)\left(\sigma_{s u}-\sigma_{s u^{*}}\right) \\
& -n(1-n)(1-2 \varepsilon)\left(\sigma_{s v}-\sigma_{s v^{*}}\right)+(1-n) \sigma_{c^{*} u}+n \sigma_{c^{*} u^{*}} \\
& +(\varepsilon(1-n)+n(1-\varepsilon)) \sigma_{c^{*} v}+((1-n)(1-\varepsilon)+\varepsilon n) \sigma_{c^{*} v^{*}} \\
& -\left(\frac{(1-n) \varepsilon^{2}}{2}+\frac{n(1-\varepsilon)^{2}}{2}\right) \sigma_{v}^{2}-\left(\frac{(1-n)(1-\varepsilon)^{2}}{2}+\frac{n \varepsilon^{2}}{2}\right) \sigma_{v^{*}}^{2} \\
& -\frac{(1-n)}{2} \sigma_{u}^{2}-\frac{n}{2} \sigma_{u^{*}}^{2}-\varepsilon(1-n) \sigma_{u v}-n \varepsilon \sigma_{u^{*} v^{*}}
\end{aligned}
$$

Since home currency is designated as a reference currency, home CPI index is insulated from the volatility of the nominal exchange rate. As a result, foreign monetary policy can not affect the mean and volatility of home consumption, which is verified by equations (17) and (20). Foreign CPI index, however, is influenced directly by the volatility of the nominal exchange rate. Therefore, both home and foreign monetary policies can affect the mean and volatility of foreign consumption, which is showed by equations (18) and (21).

Thus a representative home household's expected utility is

$$
E U=E c-\frac{1}{\eta} E L
$$

it's foreign counterpart is

$$
E U^{*}=E c^{*}-\frac{1}{\eta} E L^{*}
$$


Using equations (14), (15), (16), (17), and (18), variance and covariance terms in equations (20) and (21) that are related to $c, c^{*}$ and $s$ can be expressed in terms of $a=\left\{a_{1}, a_{2}, a_{3}, a_{4}\right\}, b=\left\{b_{1}, b_{2}, b_{3}, b_{4}\right\}$ and exogenous variance and covariance. In a Nash game, each of the monetary authorities chooses the parameters of its monetary policy rule to maximize the expected utility of its own country's representative household, taking its counterpart's actions as given. In other words, home and foreign monetary policy makers play the following Nash game

$$
\max _{a} E U\left(a, b^{N}\right) \max _{b} E U^{*}\left(a^{N}, b\right)
$$

The solution to (24) is given by Proposition 2.

\section{Proposition 1}

The solution to problem (24) is

$$
\begin{aligned}
& a_{1}^{N}=n, a_{2}^{N}=1-n, a_{3}^{N}=n \varepsilon+(1-n)(1-\varepsilon), a_{4}^{N}=n(1-\varepsilon)+\varepsilon(1-n), \\
& b_{1}^{N}=0, b_{2}^{N}=1, b_{3}^{N}=1-\varepsilon, b_{4}^{N}=\varepsilon .
\end{aligned}
$$

Proof.

$$
\text { See Appendix. }{ }^{6}
$$

In a standard monetary model in which prices are flexible, monetary policy is neutral to real variables thus has no influence on the welfare. By comparison, in our model with vertical production and trade, even if prices at the lower stage are flexible, due to price stickiness at the upper stage, monetary policy needs to respond to the productivity shocks at the lower stage and still has room to improve the welfare. Specifically, if there is a positive productivity shock at the home lower stage and monetary authorities take no action, it is certain that home and foreign prices of home intermediate goods will go down due to a lower marginal cost. Consequently, home and foreign final-goods producers will increase the input of home intermediate goods due to the normal substitution and income effects, but they will reduce the input of foreign intermediate goods since home and foreign final-goods outputs keep unchanged. Thus, it means an adverse shock to foreign intermediategoods firms. In this circumstance, foreign monetary authority depreciates its currency to boost the demands for its own country's intermediate goods. However, the depreciation will depress the demands for home intermediate goods and also lower foreign demand for home final goods. In order to counterbalance the adverse effects, home monetary authority also expands money supply. As a result, the demands for home and foreign final goods increase in the home country due to the expenditure-level effect. In the foreign country, the situation is different because monetary policy has both the expenditure-level and the expenditure-switching effects. Undoubtedly, the demand for foreign final goods increases due to the expenditure-level effect from foreign monetary expansion. The demand for home final goods will increase if both the expenditure-level and the expenditure-switching effects work in the same direction, this case occurs when $\varepsilon>1 / 2$, i.e. home currency depreciates relative to foreign currency. ${ }^{7}$ Otherwise, the demand for home final goods will depend on which effect is greater. Through vertical linkages, the effects of monetary policies on final goods will be passed on to the lower stage. Since outputs at the both stages are inefficiently low due to monopolistic distortions, facing a positive productivity shock at the lower stage no matter where it originates from, monetary authorities can improve the welfare by expanding the money supply even if the prices at the lower stage are flexible.

After introducing RCP into DE (2003), DSX (2007) draw a conclusion that foreign monetary authority does not need to respond to productivity shock from the home country. The above analysis implies that, after introducing vertical production and trade, their conclusion is modified. To be specific, if the shock is from home upper stage of the production, then their conclusion remains valid, however, if the shock is from home lower stage of the production, home monetary authority's response will cause the externality passed through the vertical production and trade, thus, foreign monetary authority needs to respond to the shock.

As emphasized in SX (2007), it seems that the introduction of vertical production and trade implies that there are gains from cooperation between global monetary authorities. However, their assumption of PCP at the upper stage implies that there are no gains from cooperation. After we introduce RCP, their conclusion does not hold any more. Now we discuss optimal monetary policy rules under cooperation. When the monetary policy rules can be chosen cooperatively, the following maximization problem needs to be solved

$$
\max _{a^{C}, b^{C}} E V\left(a^{C}, b^{C}\right)=\frac{1}{2} E U\left(a^{C}, b^{C}\right)+\frac{1}{2} E U^{*}\left(a^{C}, b^{C}\right)
$$

Solving the maximization problem (25), we have 


\section{Proposition 2}

The solution to problem (25) is

$$
\begin{aligned}
& a_{1}^{C}=\frac{1}{2-n}, a_{2}^{C}=\frac{1-n}{2-n}, a_{3}^{C}=\frac{1-n+n \varepsilon}{2-n}, a_{4}^{C}=\frac{1-n+n(1-\varepsilon)}{2-n} \\
& b_{1}^{C}=0, b_{2}^{C}=1, b_{3}^{C}=1-\varepsilon, b_{4}^{C}=\varepsilon
\end{aligned}
$$

Proof.

See Appendix.

Note in RCP case, foreign monetary policy has no effect on home consumption, in addition, the utility from employment is constant for both countries, thus, foreign monetary responses under cooperation are the same as those in Nash case. By comparison, home monetary policy will influence foreign consumption by the channel of the exchange rate pass-through, when the monetary policy is chosen cooperatively, the effect on foreign will be taken into account, thus, home monetary responses under cooperation are different from those in Nash case.

When households in both countries only buy their domestic final goods, i.e. there are no international trade in final goods $(n=1)$, Nash solution is identical to cooperative solution, thus, there are no gains from cooperation in this unrealistic case. ${ }^{8}$

Generally, when there are international trade in final goods $(n \neq 1)$, home Nash response to a positive productivity shock from home upper stage of the production is smaller than that in cooperative case. ${ }^{9}$ Why? As emphasized previously, in this circumstance, home monetary authority needs to expand money supply to boost the demands for home final goods, however, home households will also consume more foreign final goods by the expenditure-level effect caused by home monetary expansion. Because home monetary policy can influence foreign consumption by the channel of exchange rate pass-through, the depreciation of home currency induces foreign households to consume more home final goods with the consumption of foreign final goods being unaffected. ${ }^{10}$ This means that home monetary authority's response produces a positive externality to the foreign which is not internalized by home when playing Nash game. Consequently, its Nash response is smaller than that in cooperative case.

When a positive productivity shock is from foreign upper stage of the production, home Nash response is greater than that in cooperative case. ${ }^{11}$ What is the intuition? In RCP case, when facing a positive productivity shock from the upper stage of the domestic production, foreign monetary authority needs an aggressive monetary expansion. The reason is that foreign monetary policy has no effects on home consumption, and foreign monetary authority can only depend on its domestic expenditure-level and expenditure-switching effects. However, a substantial depreciation of foreign currency reduces home export. In order to counteract, home monetary authority expands money supply less aggressively than its foreign counterpart. To some extent, home monetary authority's response causes its foreign counterpart's effort to be less effective. And its Nash response, which aims to maximize home representative household's welfare, unlike cooperative one, doesn't consider its adverse effect on foreign. Accordingly, home Nash response is greater than that in cooperative case.

A classical question in the open economy macroeconomics literature is whether there are gains from monetary cooperation between monetary authorities. The conclusion is mixed. ${ }^{12}$ Even though many researchers find that gains from monetary cooperation exist, a realistic question is ignored by all researchers, are the involving countries willing to participate in the cooperation? Equivalently, are they better off after participating in the cooperation than playing a Nash game? If a country becomes worse off after taking part in the cooperation, then it is not realistic to expect it to engage in a cooperative agreement. In the paper, we fill the gap and give a condition under which the monetary cooperation is realistic in the sense that the utility levels of the households in both countries are greater after taking part in the cooperation than playing a Nash game.

Without loss of generality, In Proposition 3, we suppose that there is no home bias both in consumption and production to keep the calculation as simple as possible. In other words, $n=\varepsilon=1 / 2$ is assumed.

\section{Proposition 3}

1. If $\sigma_{u v}>0$, then there are gains from cooperation. Moreover, foreign is willing to cooperate unconditionally, but home is willing to cooperate only under the condition that $\sigma_{u v}>\frac{1}{36} \sigma^{2}$.

2. If $\sigma_{u v}<0$, then there are gains from cooperation only when $\sigma^{2}>-48 \sigma_{u v}$. But, in this case, home is not willing to cooperate any more. Foreign, as before, is still willing to cooperate.

Proof.

(1). When monetary policy rules are chosen by Nash players, the welfare of a home representative household is 


$$
E U=-\ln \left(\eta \lambda_{m} \phi_{m}\right)-\frac{1}{\lambda_{m} \phi_{m}}-\frac{1}{4} \sigma^{2},
$$

for a foreign representative household, it is

$$
E U^{*}=-\ln \left(\eta \lambda_{m} \phi_{m}\right)-\frac{1}{\lambda_{m} \phi_{m}}-\frac{1}{8} \sigma^{2} .
$$

When monetary policy rules are set cooperatively, then the counterparts of equations (26) and (27) are respectively

$$
\begin{gathered}
E U=-\ln \left(\eta \lambda_{m} \phi_{m}\right)-\frac{1}{\lambda_{m} \phi_{m}}-\frac{5}{18} \sigma^{2}+\sigma_{u v} \\
E U^{*}=-\ln \left(\eta \lambda_{m} \phi_{m}\right)-\frac{1}{\lambda_{m} \phi_{m}}-\frac{1}{18} \sigma^{2}+\sigma_{u v} .
\end{gathered}
$$

If $\sigma_{u v}>0$, then $(28)+(29)>(26)+(27)$ holds. Therefore, there are gains from cooperation. Moreover, $(29)>(27)$ holds, it means that foreign households are better off if the monetary policy is set cooperatively. Thus foreign is willing to take part in cooperation. Similarly, if $\sigma_{u v}>\frac{1}{36} \sigma^{2}$, then (28) $>(26)$ holds, home prefers cooperation as well.

(2). If $\sigma_{u v}<0,(28)+(29)>(26)+(27)$ holds only when $\sigma^{2}>-48 \sigma_{u v}$. Furthermore, $(28)<(26)$ holds, it means that home households are worse off if the monetary policy is set cooperatively. Therefore, home refuses cooperation even if there are gains from cooperation. But under the condition $\sigma^{2}>-48 \sigma_{u v}$, we have (29) > (27), thus, foreign is still willing to cooperate.

Only if the utility levels of the households in both countries are greater after taking part in monetary cooperation than playing a Nash game, the gains from monetary cooperation can be achieved. If the gains can be achieved, we call the gains from monetary cooperation to be real, otherwise, the gains are false. In the literature, for the first time, we discuss the problem and give such a condition. To be specific, if the covariance between productivity shocks at the two stages is greater than zero, furthermore, if the covariance is greater than a proportion of the variance $\left(\sigma_{u v}>\frac{1}{36} \sigma^{2}\right)$, then the gains from cooperation are real. In this circumstance, the aggregate gains from cooperation are $\frac{1}{24} \sigma^{2}+2 \sigma_{u v}$, and both countries can benefit from participating in the cooperation. The home and foreign households' utility levels increase by $\sigma_{u v}-\frac{1}{36} \sigma^{2}$ and $\frac{5}{72} \sigma^{2}+\sigma_{u v}$ respectively relative to their counterparts in a Nash case. Otherwise, if the covariance between productivity shocks at the two stages is less than zero, only when the variance is large enough are there gains from cooperation. But the gains from cooperation can not be achieved since home is better off by playing a Nash game.

By comparison, when there is no vertical production and trade, ${ }^{13}$ i.e. $\varepsilon=1, \theta_{i}=\theta_{i}^{*}=1$, the gains from monetary cooperation are false. When vertical production and trade is absent, we can follow the same procedure and solve for the optimal monetary policy rules both in Nash and cooperative cases. In Nash case, they are given by $a_{1}^{N}=n, a_{2}^{N}=1-n, b_{1}^{N}=0, b_{2}^{N}=1$; in cooperative case, they are $a_{1}^{C}=\frac{1}{2-n}, a_{2}^{C}=\frac{1-n}{2-n}, b_{1}^{C}=0, b_{2}^{C}=1$. In order to make a comparison with Proposition 3 , we set $n=1 / 2$. In this circumstance, when monetary policy rules are chosen by Nash players, the utility levels of home and foreign households are respectively: $E U^{N}=-\ln \left(\eta \lambda_{m}\right)-$ $\frac{1}{\lambda_{m}}-\frac{1}{4} \sigma^{2}, E U^{* N}=-\ln \left(\eta \lambda_{m}\right)-\frac{1}{\lambda_{m}}-\frac{1}{8} \sigma^{2}$; when monetary policy rules are chosen by cooperative players, the utility levels of home and foreign households are respectively: $E U^{C}=-\ln \left(\eta \lambda_{m}\right)-\frac{1}{\lambda_{m}}-\frac{5}{18} \sigma^{2}, E U^{* C}=$ $-\ln \left(\eta \lambda_{m}\right)-\frac{1}{\lambda_{m}}-\frac{1}{18} \sigma^{2}$. After a simple calculation, we have $E U^{C}+E U^{* C}>E U^{N}+E U^{* N}$. This implies that even though there is no vertical production and trade, the gains from monetary cooperation still exist. However, we have $E U^{N}>E U^{C}, E U^{* N}<E U^{* C}$. This implies that the foreign country is willing to take part in cooperation but the home country is not willing to. In this sense, the gains from monetary cooperation are false. ${ }^{14}$

In the literature, for the first time, our model produces real gains from monetary cooperation when the utility function of consumption is logarithmic. In OR (2000), DE (2003), SX (2007), there are no gains from monetary cooperation. The same conclusion also holds in OR (2002), Clarida, Gali, and Gertler (2002) when the utility function of consumption is logarithmic. But there are several exceptions in which the gains from monetary cooperation emerge even if the utility function of consumption is logarithmic. In CP (2005), except for several extreme cases, the gains from monetary cooperation exist for a general exchange rate pass-through elasticity. However, how big are the gains and whether are they real? the authors consider them as open issues. In Liu 
and Pappa (2008), the usual the terms-of-trade externality produces the gains from monetary cooperation, in addition, they also emerge from the terms-of-trade bias to the country with a larger traded sector. But the authors do not consider whether the gains are real. By comparison, in our model, pure reference currency pricing without vertical production and trade leads to different policy effectiveness for home and foreign monetary authorities, thus the gains from monetary cooperation emerge but they are false. When we introduce vertical production and trade, a productivity shock from the lower stage of the production causes global effects via vertical production and trade, consequently, the gains from monetary cooperation turn from false to real under the condition that $\sigma_{u v}>\frac{1}{36} \sigma^{2}$ holds.

Does the monetary cooperation result in less volatile nominal exchange rates? The problem is discussed in OR (2002) and the answer depends on the coefficient of relative risk aversion. When it is strictly less than unity, the volatility of the nominal exchange rate in Nash case is excessive relative to that in cooperative case. When it is strictly greater than unity, the Nash case leads to a more stable nominal exchange rate than does the cooperative case. What is the answer when the coefficient of relative risk aversion is exactly unity? The problem is open as yet. In this paper, we have the following conclusion. ${ }^{15}$

\section{Proposition 4}

1. If $n=1$, then $\operatorname{var}\left(s^{N}\right)=\operatorname{var}\left(s^{C}\right)$.

2. If $n \neq 1$, in addition, either $\sigma_{u v}=0$ or $\varepsilon=1 / 2$ holds, then $\operatorname{var}\left(s^{N}\right)<\operatorname{var}\left(s^{C}\right)$.

3. If $n \neq 1$, in addition, either $\sigma_{u v}>0$ and $\varepsilon>1 / 2$ or $\sigma_{u v}<0$ and $\varepsilon<1 / 2$ holds, then $\operatorname{var}\left(s^{N}\right)<\operatorname{var}\left(s^{C}\right)$.

4. If $n \neq 1$, in addition, either $\sigma_{u v}<0$ and $\varepsilon>1 / 2$ or $\sigma_{u v}>0$ and $\varepsilon<1 / 2$ holds, there are two cases. When $\sigma^{2} \leq \frac{2(1-2 \varepsilon)}{1+(1-2 \varepsilon)^{2}} \sigma_{u v}$, then $\operatorname{var}\left(s^{N}\right) \geq \operatorname{var}\left(s^{C}\right)$. When $\sigma^{2}>\frac{2(1-2 \varepsilon)}{1+(1-2 \varepsilon)^{2}} \sigma_{u v}$, then $\operatorname{var}\left(s^{N}\right)<\operatorname{var}\left(s^{C}\right)$.

Proof.

In Nash case, the nominal exchange rate can be expressed as

$$
\begin{aligned}
S^{N} & =\frac{M}{M^{*}}=\frac{\exp \left(n u+(1-n) u^{*}+(n \varepsilon+(1-n)(1-\varepsilon)) v+(n(1-\varepsilon)+(1-n) \varepsilon) v^{*}\right)}{\exp \left(u^{*}+(1-\varepsilon) v+\varepsilon v^{*}\right)} \\
& =\exp \left(n u-n u^{*}-n(1-2 \varepsilon) v+n(1-2 \varepsilon) v^{*}\right) .
\end{aligned}
$$

In cooperative case, the nominal exchange rate can be expressed as

$$
\begin{aligned}
S^{C} & =\frac{M}{M^{*}}=\frac{\exp \left(\frac{1}{2-n} u+\frac{1-n}{2-n} u^{*}+\frac{1-n+n \varepsilon}{2-n} v+\frac{1-n+n(1-\varepsilon)}{2-n} v^{*}\right)}{\exp \left(u^{*}+(1-\varepsilon) v+\varepsilon v^{*}\right)} \\
& =\exp \left(\frac{1}{2-n} u-\frac{1}{2-n} u^{*}-\frac{1-2 \varepsilon}{2-n} v+\frac{1-2 \varepsilon}{2-n} v^{*}\right) .
\end{aligned}
$$

From equation (30), we have $s^{N}=\ln S^{N}=n u-n u^{*}-n(1-2 \varepsilon) v+n(1-2 \varepsilon) v^{*}$. It implies that var $\left(s_{N}\right)=2 n^{2}(1+$ $\left.(1-2 \varepsilon)^{2}\right) \sigma^{2}-4 n^{2}(1-2 \varepsilon) \sigma_{u v}$. Similarly, from equation (31), we have $s^{C}=\ln S^{C}=\frac{1}{2-n} u-\frac{1}{2-n} u^{*}-\frac{1-2 \varepsilon}{2-n} v+\frac{1-2 \varepsilon}{2-n} v^{*}$. It implies that $\operatorname{var}\left(S^{C}\right)=\frac{2\left(1+(1-2 \varepsilon)^{2}\right)}{(2-n)^{2}} \sigma^{2}-\frac{4(1-2 \varepsilon)}{(2-n)^{2}} \sigma_{u v}$. The rest of the proof involving the comparison between $\operatorname{var}\left(s^{N}\right)$ and $\operatorname{var}\left(s^{C}\right)$ is straightforward and thus omitted.

Thus, in our model, the answer depends on the covariance of the shock at the upper stage of the production with that at the lower stage of the production and home bias in production. ${ }^{16}$ When the covariance is equal to zero, our conclusion in Proposition 4 is the same as that without vertical production and trade, the difference is that both $\operatorname{var}\left(s^{N}\right)$ and $\operatorname{var}\left(s^{C}\right)$ are magnified with a proportion of $1+(1-2 \varepsilon)^{2}$. If there is no vertical production and trade, in RCP case, the expenditure-switching effect only works in foreign markets. When the monetary policy rules are chosen cooperatively, the monetary policy maker will make better use of the expenditureswitching effect to improve the welfare levels of households in both countries. Consequently, a more volatile exchange rate is needed. When there is no home bias in production, monetary responses to productivity shocks at the lower stage of the production do not affect the volatility of the nominal exchange rates in both Nash and cooperative cases. Therefore, the conclusion obtained in the case of no vertical production and trade still holds. When the covariance is strictly greater than zero and final-goods producers bias towards domestic intermediate goods, or the covariance is strictly less than zero and final-goods producers bias towards imported intermediate goods, the introduction of vertical production and trade will make the nominal exchange rates in both Nash and cooperative cases more volatile but does not change the ordering between them. When the covariance is 
strictly less than zero and final-goods producers bias towards domestic intermediate goods, or the covariance is strictly greater than zero and final-goods producers bias towards imported intermediate goods, two outcomes arise. Intuitively, after vertical production and trade is introduced, flexible prices at the lower stage of the production permit full exchange-rate pass-through. After a positive productivity shock occurs at the home lower stage of the production, it tends to lower home intermediate-goods prices facing a foreign final-goods producer through the channel of marginal cost. Meanwhile, an expansionary response of home monetary authority will further lower home intermediate-goods prices facing a foreign final-goods producer through the channel of the nominal exchange rate. These two effects operate in the same direction and affect the foreign adversely. When monetary policy rules are chosen cooperatively, the monetary policy maker will avoid an excessively volatile exchange rate at the lower stage of the production. Thus, when choosing the monetary policy rules cooperatively, the monetary policy maker faces a trade-off. For one thing, she wants a more volatile exchange rate at the upper stage of the production to take advantage of the one-sided expenditure-switching effect. For another, she wants a less volatile exchange rate at the lower stage of the production to avoid the negative externality of the monetary policy. When $\sigma^{2} \leq \frac{2(1-2 \varepsilon)}{1+(1-2 \varepsilon)^{2}} \sigma_{u v}$, the desire to avoid a more volatile exchange rate at the lower stage of the production dominates thus the volatility of the nominal exchange rate in cooperative case is less than or equal to that in Nash case. When $\sigma^{2}>\frac{2(1-2 \varepsilon)}{1+(1-2 \varepsilon)^{2}} \sigma_{u v}$, the desire to have a more volatile exchange rate at the upper stage of the production dominates thus the volatility of the nominal exchange rate in cooperative case is greater than that in Nash case.

SX (2007) find that, in PCP case, after vertical production and trade is introduced into an otherwise standard sticky-price model, the nominal exchange rate is more stable. After we introduce RCP and suppose flexible prices at the lower stage of the production, does the same conclusion hold? ${ }^{17}$

\section{Proposition 5}

1. If $\varepsilon=1 / 2$, then $\operatorname{var}\left(s^{V}\right)=\operatorname{var}\left(s^{N V}\right)$.

2. If $\sigma_{u v}=0$, then $\operatorname{var}\left(s^{V}\right) \geq \operatorname{var}\left(s^{N V}\right)$.

3. If either $\sigma_{u v}<0$ and $\varepsilon<1 / 2$ or $\sigma_{u v}>0$ and $\varepsilon>1 / 2$ holds, then $\operatorname{var}\left(s^{V}\right)>\operatorname{var}\left(s^{N V}\right)$.

4. If either $\sigma_{u v}<0$ and $\varepsilon>1 / 2$ or $\sigma_{u v}>0$ and $\varepsilon<1 / 2$ holds, there are two cases. When $\sigma^{2} \geq \frac{2}{1-2 \varepsilon} \sigma_{u v}$, then var $\left(s^{V}\right)$ $\geq \operatorname{var}\left(s^{N V}\right)$. Otherwise when $\sigma^{2}<\frac{2}{1-2 \varepsilon} \sigma_{u v}$, then $\operatorname{var}\left(s^{V}\right)<\operatorname{var}\left(s^{N V}\right)$.

Proof.

The expression of the nominal exchange rate when there is vertical production and trade is given by equation (30). Thus, its volatility is $\operatorname{var}\left(s_{N}\right)=2 n^{2}\left(1+(1-2 \varepsilon)^{2}\right) \sigma^{2}-4 n^{2}(1-2 \varepsilon) \sigma_{u v}$.

By comparison, if there is no vertical production and trade, the nominal exchange rate can be expressed as

$$
S^{N V}=\frac{M}{M^{*}}=\frac{\exp \left(a_{1}^{N} u+a_{2}^{N} u^{*}\right)}{\exp \left(b_{1}^{N} u+b_{2}^{N} u^{*}\right)}=\frac{\exp \left(n u+(1-n) u^{*}\right)}{\exp \left(u^{*}\right)}=\exp \left(n u-n u^{*}\right) .
$$

From equation (32), we have $s^{N V}=\ln S^{N V}=n u-n u^{*}$. This implies that $\operatorname{var}\left(s^{N V}\right)=2 n^{2} \sigma^{2}$. By the same reason given in Proposition 4, we omit the rest of the proof.

Thus, our conclusion contrasts sharply with that in SX (2007). SX (2007) argue that, when a country is more integrated in production and trade with other countries, there is no need for a volatile nominal exchange rate to respond to shocks. However, Proposition 5 tells us that the nominal exchange rate does not always become more stable when there is vertical production and trade. Why?

In our model, monetary responses to productivity shocks at the upper stage of the production are the same as those when there is no vertical production and trade. Thus monetary responses to productivity shocks at the lower stage of the production are key to understand the difference between the volatility of the nominal exchange rate when there is no vertical production and trade and that when there is vertical production and trade.

When there is no home bias in production, monetary responses to productivity shocks at the lower stage of the production do not affect the volatility of the nominal exchange rate. Therefore, the volatility of the nominal exchange rate when there is vertical production and trade is the same as that when there is no vertical production and trade. When the covariance of the shock at the upper stage of the production with that at the lower stage of the production is zero, the interaction between shocks at the upper and the lower stages disappears, the volatility of the nominal exchange rate when there is vertical production and trade is greater than that when there is no vertical production and trade. Intuitively, when there is an additional shock to deal with which 
does not interact with the existing shocks, under the condition that the monetary responses to the new shock does not affect the monetary responses to the existing shocks, the monetary responses to the new shock will make the nominal exchange rate more volatile. In this case, the greater volatility comes from the dimension effect of the monetary policy. In our model, the dimension effect always magnifies the volatility of the nominal exchange rate.

When the covariance is strictly less than zero and final-goods producers bias towards imported intermediate goods, or the covariance is strictly greater than zero and final-goods producers bias towards domestic intermediate goods, the monetary responses to the existing and additional new shocks result in a situation in which the interaction between shocks makes the nominal exchange rate more volatile. In this case, besides the dimension effect, there is a new effect contributing to the greater volatility which we call the interaction effect. The direction of the interaction effect depends on the covariance and home bias in production.

When the covariance is strictly less than zero and final-goods producers bias towards home intermediate goods, or the covariance is strictly greater than zero and final-goods producers bias towards imported intermediate goods, unlike the dimension effect, the interaction effect tends to lower the volatility of the nominal exchange rate. The final volatility depends on which effect is greater. When $\sigma^{2} \geq \frac{2}{1-2 \varepsilon} \sigma_{u v}$, the dimension effect dominates the interaction effect, and the volatility of the nominal exchange rate when there is vertical production and trade is more volatile than that when there is no vertical production and trade. When $\sigma^{2}<\frac{2}{1-2 \varepsilon} \sigma_{u v}$, the interaction effect dominates the dimension effect, and the volatility of the nominal exchange rate when there is vertical production and trade is less volatile than that when there is no vertical production and trade.

In SX (2007), the authors only consider a special case in which there is no home bias in both consumption and production. Thus the dimension effect does not magnify the volatility of the nominal exchange rate, on the contrary, it lowers the volatility. When the covariance is strictly greater than zero, the interaction effect can increase the volatility, but the increase falls short of the decrease from the dimension effect. As a result, the exchange rate is less volatile after vertical production and trade is introduced.

\section{Extension: dual price stickiness}

In the literature of New Keynesian monetary economics, price stickiness plays an important role in determining optimal monetary policy. Our conclusions obtained in the benchmark model crucially depend on the assumption that final-goods prices are sticky but intermediate-goods prices are flexible. What happens when both of them are sticky? In order to answer the question, we extend the model to allow for dual price stickiness.

When both final-goods prices and intermediate-goods prices are sticky, except for intermediate-goods prices, other equations in the equilibrium system are the same as those in the benchmark model. The expressions for intermediate-goods prices are given in Table 3.

Table 3: Optimal intermediate-goods prices in the extension model.

\begin{tabular}{lc}
$P_{H H i}=\frac{\lambda}{\lambda-1} \frac{E\left(\frac{W}{\theta_{i} \theta_{f}}\right)}{E\left(\frac{1}{\theta_{f}}\right)}$ & $P_{H F i}=\frac{\lambda}{\lambda-1} \frac{E\left(\frac{W S^{\varepsilon}}{\theta_{i}^{*} \theta_{f}^{*}}\left((1-n) P_{F H f}^{-1}+n S^{-1} P_{F F f}^{*-1}\right)\right)}{E\left(\frac{S^{\varepsilon}}{\theta_{f}^{*}}\left((1-n) P_{F H f}^{-1}+n S^{-1} P_{F F f}^{*-1}\right)\right)}$ \\
$P_{F H i}=\frac{\lambda}{\lambda-1} \frac{E\left(\frac{W^{*} S}{\theta_{i}^{*} \theta_{f}}\right)}{E\left(\frac{1}{\theta_{f}}\right)}$ & $P_{F F i}^{*}=\frac{\lambda}{\lambda-1} \frac{E\left(\frac{W^{*} \mathcal{S}^{\varepsilon-1}}{\theta_{i}^{*} \theta_{f}^{*}}\left((1-n) P_{F H f}^{-1} S+n P_{F F f}^{*-1}\right)\right)}{E\left(\frac{S^{\varepsilon-1}}{\theta_{f}^{*}}\left((1-n) P_{F H f}^{-1} S+n P_{F F f}^{*-1}\right)\right)}$ \\
\hline
\end{tabular}

The extension makes it impossible to derive the model's closed-form solution as we did in the benchmark model. We follow the convention in the literature to log-linearize the equilibrium system whereas approximate the welfare around the non-stochastic steady state up to a second order. The non-stochastic steady state follows when $\theta_{f}=\theta_{f}^{*}=\theta_{i}=\theta_{i}^{*}=1$. In order to obtain an efficient steady state, we assume that the distortions caused by monopoly are eliminated by government's subsidies which are financed by a lump-sum tax. In the following, a variable $X$ with a hat denotes the log-deviation from its non-stochastic steady state $\bar{X}$, i.e. $\widehat{X}=\log \left(\frac{X}{\bar{X}}\right)$.

In order to save the space, we omit a complete description of the log-linearized equilibrium system and directly present several equations which are indispensable for solving welfare maximization games played by monetary authorities.

From log-linearized money demand functions and log-linearized risk-sharing condition, we have

$$
\widehat{S}=\widehat{M}-\widehat{M^{*}}+O\left(\|\xi\|^{2}\right),
$$


in which $O\left(\|\xi\|^{n}\right)$ indicates terms that are of order higher than $n$ th. As in the benchmark model, currency depreciation follows from monetary expansion.

Using log-linearized expressions of home consumer price index and home money demand equation, we can express home consumption as

$$
\begin{aligned}
\widehat{C}= & \widehat{M}-E \widehat{M}+n E \widehat{\theta_{f}}+(1-n) E \widehat{\theta_{f}^{*}}+(n \varepsilon+(1-n)(1-\varepsilon)) E \widehat{\theta_{i}} \\
& +(n(1-\varepsilon)+(1-n) \varepsilon) E \widehat{\theta_{i}^{*}}+O\left(\|\xi\|^{2}\right) .
\end{aligned}
$$

Similarly, equation (34)'s foreign counterpart can be expressed as

$$
\begin{aligned}
\widehat{C^{*}}= & (1-n)(\widehat{M}-E \widehat{M})+n\left(\widehat{M^{*}}-E \widehat{M^{*}}\right)+(1-n) E \widehat{\theta_{f}}+n E \widehat{\theta_{f}^{*}} \\
& +(\varepsilon(1-n)+n(1-\varepsilon)) E \widehat{\theta_{i}}+((1-n)(1-\varepsilon)+n \varepsilon) E \widehat{\theta_{i}^{*}}+O\left(\|\xi\|^{2}\right) .
\end{aligned}
$$

As in the benchmark model, when home currency acts as a reference currency, foreign monetary policy cannot influence home consumption. By comparison, both home and foreign monetary policies can influence foreign consumption. This implies that, in final-goods markets, the expenditure-switching effect is unilateral and only works in the foreign country.

From home market-clearing condition, equations (33) and (34), and home log-linearized consumer price index, log-linearized final-goods and intermediate-goods price indexes in both countries, home employment can be expressed as

$$
\begin{aligned}
\widehat{L}= & {[1+(1-\varepsilon)(\varepsilon(1-n)-n(1-\varepsilon))] \widehat{M}-(1-\varepsilon)(\varepsilon(1-n)-n(1-\varepsilon)) \widehat{M^{*}} } \\
& -((1-n)+\varepsilon n+\varepsilon(1-\varepsilon)) E \widehat{M}+(1-\varepsilon)(\varepsilon-n) E \widehat{M^{*}}+E \widehat{\theta_{i}}+\varepsilon E \widehat{\theta_{f}} \\
& +(1-\varepsilon) E \widehat{\theta_{f}^{*}}-\widehat{\theta_{i}}-\varepsilon \widehat{\theta_{f}}-(1-\varepsilon) \widehat{\theta_{f}^{*}}+O\left(\|\xi\|^{2}\right) .
\end{aligned}
$$

Equation (36) implies that the supply of home intermediate goods is equal to the demands for them. Via vertical production and trade, both home and foreign final-goods producers demand home intermediate goods. An increase in the productivity of home intermediate-goods producers will raise the supply of home intermediate goods thus lower the demand for home labor. When the productivity of home final-goods producers increases, they will reduce the demand for home intermediate goods, equivalently, for home labor. The extent to which the productivity of home final-goods producers influences the demand for home labor depends on home bias in home final-goods production. The effect of the productivity of foreign final-goods producers on the demand for home labor can be analyzed similarly. Home monetary policy influences the demands for home labor through three channels, one works in the home country and another two work in the foreign country. An expansionary home money supply increases home households' demands for both home and foreign final goods through the expenditure-level effect. Consequently, home and foreign final-goods producers raise the input of home intermediate goods. Thus the demands for home labor increase. In the foreign country, a home expansionary money supply changes the demands for home labor through two expenditure-switching effects, one in final-goods market and the other in intermediate-goods market. As a comparison, foreign monetary policy cannot influence the home country, it affects the demands for home labor through the expenditure-level and the expenditure-switching effects in domestic final-goods market and the expenditure-switching effect in domestic intermediate-goods market.

Equation (36)'s foreign counterpart is

$$
\begin{aligned}
\widehat{L^{*}}= & {\left[(1-\varepsilon)+\varepsilon^{2}(1-n)-\varepsilon(1-\varepsilon) n\right] \widehat{M}+\left[1-\left((1-\varepsilon)+\varepsilon^{2}(1-n)-\varepsilon(1-\varepsilon) n\right)\right] \widehat{M^{*}} } \\
& +[(1-\varepsilon)(\varepsilon-n)-(1-n)] E \widehat{M}-[\varepsilon n+\varepsilon(1-\varepsilon)] E \widehat{M^{*}}+E \widehat{\theta_{i}^{*}}+\varepsilon E \widehat{\theta_{f}^{*}} \\
& +(1-\varepsilon) E \widehat{\theta_{f}}-\widehat{\theta_{i}^{*}}-(1-\varepsilon) \widehat{\theta_{f}}-\varepsilon \widehat{\theta_{f}^{*}}+O\left(\|\xi\|^{2}\right) .
\end{aligned}
$$

The economic implication of equation (37) is similar to that of equation (36).

Following the literature, we assume that the utility of the real balances is small thus can be neglected. ${ }^{18}$ Taking the second-order approximation to a home representative household's utility, we have

$$
U=\bar{U}+E\left[\widehat{C}-\eta \bar{L}\left(\hat{L}+\frac{1}{2} \hat{L}^{2}\right)\right]+O\left(\|\xi\|^{3}\right)
$$


in which $\bar{L}=1 / \eta$. From equations (34) and (36), we know even if foreign monetary policy cannot influence home consumption, it can influence home employment after vertical production and trade is introduced into a monetary model with RCP. Thus, unlike the benchmark model, foreign monetary policy can influence home welfare when the utility function is approximated up to a second order.

\subsection{Optimal monetary policy rules}

Similar to the benchmark model, home and foreign monetary policy rules are given respectively by

$$
\begin{aligned}
& \widehat{M}=a_{1} \widehat{\theta_{f}}+a_{2} \widehat{\theta_{f}^{*}}+a_{3} \widehat{\theta_{i}}+a_{4} \widehat{\theta_{i}^{*}}, \\
& \widehat{M^{*}}=b_{1} \widehat{\theta_{f}}+b_{2} \widehat{\theta_{f}^{*}}+b_{3} \widehat{\theta_{i}}+b_{4} \widehat{\theta_{i}^{*}} .
\end{aligned}
$$

Using equations (34), (36), (38), (39), (40), and noting $E \widehat{\theta_{f}}=E \widehat{\theta_{f}^{*}}=E \widehat{\theta_{i}}=E \widehat{\theta_{i}^{*}}=0$, a home representative household's utility can be expressed as

$$
\begin{aligned}
U(a, b)= & \bar{U}-\frac{1}{2} E\left\{\left[a_{1}-\varepsilon+(1-\varepsilon)(\varepsilon(1-n)-n(1-\varepsilon))\left(a_{1}-b_{1}\right)\right] \widehat{\theta_{f}}\right. \\
& +\left[a_{2}-(1-\varepsilon)+(1-\varepsilon)(\varepsilon(1-n)-n(1-\varepsilon))\left(a_{2}-b_{2}\right)\right] \widehat{\theta_{f}^{*}} \\
& +\left[a_{3}-1+(1-\varepsilon)(\varepsilon(1-n)-n(1-\varepsilon))\left(a_{3}-b_{3}\right)\right] \widehat{\theta_{i}} \\
& \left.+\left[a_{4}+(1-\varepsilon)(\varepsilon(1-n)-n(1-\varepsilon))\left(a_{4}-b_{4}\right)\right] \widehat{\theta}_{i}^{*}\right\}^{2} .
\end{aligned}
$$

Similarly, a foreign representative household's utility can be expressed as

$$
\begin{aligned}
U^{*}(a, b)= & \overline{U^{*}}-\frac{1}{2} E\left\{\left[b_{1}-(1-\varepsilon)+\left((1-\varepsilon)+\varepsilon^{2}(1-n)-\varepsilon(1-\varepsilon) n\right)\left(a_{1}-b_{1}\right)\right] \widehat{\theta_{f}}\right. \\
& +\left[b_{2}-\varepsilon+\left((1-\varepsilon)+\varepsilon^{2}(1-n)-\varepsilon(1-\varepsilon) n\right)\left(a_{2}-b_{2}\right)\right] \widehat{\theta_{f}^{*}} \\
& +\left[b_{3}+\left((1-\varepsilon)+\varepsilon^{2}(1-n)-\varepsilon(1-\varepsilon) n\right)\left(a_{3}-b_{3}\right)\right] \widehat{\theta_{i}} \\
& \left.+\left[b_{4}-1+\left((1-\varepsilon)+\varepsilon^{2}(1-n)-\varepsilon(1-\varepsilon) n\right)\left(a_{4}-b_{4}\right)\right] \widehat{\theta_{i}^{*}}\right\}^{2}
\end{aligned}
$$

Because the non-stochastic steady state is efficient, home monetary authority chooses $a=\left\{a_{1}, a_{2}, a_{3}, a_{4}\right\}$ to minimize the absolute value of the difference between $U$ and $\overline{\mathrm{U}}$, taking $b=\left\{b_{1}, b_{2}, b_{3}, b_{4}\right\}$ as given. Foreign monetary authority also faces the same problem. In other words, home and foreign monetary policy makers play the following Nash game:

$$
\max _{a} U\left(a, b^{N}\right)-\bar{U} \max _{b} U^{*}\left(a^{N}, b\right)-\overline{U^{*}}
$$

Solving problem (43), we have ${ }^{19}$

\section{Proposition 6}

When $\frac{1-n}{n}=\frac{1-\varepsilon}{\varepsilon}$, the solution to (43) is

$$
\begin{aligned}
& a_{1}^{N}=\varepsilon, a_{2}^{N}=1-\varepsilon, a_{3}^{N}=1, a_{4}^{N}=0, \\
& b_{1}^{N}=\frac{(1-\varepsilon)^{2}}{\varepsilon}, b_{2}^{N}=\frac{\varepsilon-(1-\varepsilon)^{2}}{\varepsilon}, \quad b_{3}^{N}=-\frac{1-\varepsilon}{\varepsilon}, b_{4}^{N}=\frac{1}{\varepsilon} .
\end{aligned}
$$

Proof.

See Appendix.

When we consider some special cases, multiple equilibria emerge. When $\varepsilon=0, n=1$, home monetary policy cannot influence home household's utility, and foreign monetary policy cannot influence foreign household's utility. Thus any pair of $a$ and $b$ constitutes a Nash equilibrium. When $\varepsilon=1, n=0$, though home monetary 
policy can influence home household's utility, foreign monetary policy cannot influence foreign household's utility. As a result, any pair of $\left\{a_{1}=1, a_{2}=0, a_{3}=1, a_{4}=0\right\}$ and $b$ constitutes a Nash equilibrium. When $\varepsilon=0$, $n \neq 1$, both home and foreign monetary policies can influence home household's utility, but foreign monetary policy cannot influence domestic utility. In this circumstance, any pair of $a$ and $b$ satisfying $(1-n) a_{1}+n b_{1}=0$, $(1-n) a_{2}+n b_{2}=1,(1-n) a_{3}+n b_{3}=1,(1-n) a_{4}+n b_{4}=0$ constitutes a Nash equilibrium.

We also consider other two cases in which the condition $\frac{1-n}{n}=\frac{1-\varepsilon}{\varepsilon}$ is not satisfied, in order to save the space, we delegate them to the appendix and just focus on what happens when $\frac{1-n}{n}=\frac{1-\varepsilon}{\varepsilon}$. Note that $\frac{1-n}{n}=\frac{1-\varepsilon}{\varepsilon}$ implies that the degree of home bias in consumption is the same as that in production.

It is worth noting that, after considering dual price stickiness, the change in solution methods completely alters the conclusions of the model. In the benchmark model, if the exogenous variables are jointly lognormal, all endogenous variables are lognormal as well. Consequently, the expected utility of employment is fixed, and monetary authority mainly pays attention to the effect of its policy on expected consumption. In the extension, on the contrary, the deviation of consumption from its steady state enters the utility function only with firstorder term, and its expected value is zero thus monetary authority does not need to focus on it. As a comparison, the deviation of employment from its steady state enters the utility function with both first-order and secondorder terms, though its expected value is zero as well, the expected square of it is not. In this circumstance, what monetary authority needs to focus on is the expected square of the deviation of employment from its steady state.

In general, the nominal exchange rate will affect the demands for home labor through two channels: it affects foreign households' choices of imported and domestic final goods, thus affects the demands for home and foreign intermediate goods, equivalently, the demands for home labor; the nominal exchange rate also directly affects foreign final-goods producers' choices of imported and domestic intermediate goods, thus influences the demands for home labor. When $\frac{1-n}{n}=\frac{1-\varepsilon}{\varepsilon}$, the combined effects of the nominal exchange rate on home labor demand is zero. As a result, home monetary authority only needs to respond to the three shocks which affect home aggregate labor demand directly, they are $\widehat{\theta_{f}}, \widehat{\theta_{f}^{*}}$ and $\widehat{\theta_{i}}$ respectively. In the foreign country, the demands for foreign final goods are from two sources: home and foreign households respectively. Though the demand for foreign final goods of home households is independent of the volatility of the nominal exchange rate, foreign households' demand is undoubtedly affected by the nominal exchange rate. The aggregate demand for foreign final goods has an impact on the demand for foreign intermediate goods thus affects the demand for foreign labor. In addition, the volatility of the nominal exchange rate will change the relative price of home and foreign intermediate goods in the foreign country thus directly affect the demand for foreign labor. When $\frac{1-n}{n}=\frac{1-\varepsilon}{\varepsilon}$, the combined effects of the nominal exchange rate on foreign labor demand through foreign intermediate-goods producers are zero. Meanwhile, the volatility of the nominal exchange rate affects the demand for home final goods of foreign households, thus via vertical production and trade, it will affect the demand for foreign labor. This effect works even under the condition $\frac{1-n}{n}=\frac{1-\varepsilon}{\varepsilon}$. This is the channel through which home monetary policy influences foreign household's welfare function when $\frac{1-n}{n}=\frac{1-\varepsilon}{\varepsilon}$. Therefore, unlike home monetary authority, foreign monetary authority not only responds to the three shocks which affect foreign aggregate labor demand directly $\left(\widehat{\theta_{f}}, \widehat{\theta_{f}^{*}}, \widehat{\theta_{i}^{*}}\right)$ but also to home monetary policy. Consequently, it also needs to respond to $\widehat{\theta_{i}}$.

In the benchmark model, when there is no home bias in consumption and production, we draw a conclusion that under the condition $\sigma_{u v}>\frac{1}{36} \sigma^{2}$, both home and foreign households are better off after participating in monetary cooperation. Thus, they are willing to take part in monetary cooperation and the gains from the cooperation are real. After we introduce dual price stickiness into the model, Are there still gains from monetary cooperation? If the answer is yes, are the gains real? ${ }^{20}$

\section{Proposition 7}

When $\frac{1-n}{n}=\frac{1-\varepsilon}{\varepsilon}$, there are no gains from monetary policy cooperation.

Proof.

See Appendix.

Thus our conclusion here contrasts sharply from what is obtained in the benchmark model. As emphasized previously, in the benchmark model, monetary authority responds to the shocks to maximize the expected utility level of consumption, whereas in the extension, monetary authority responds to the shocks to minimize the expected square of the deviation of employment from its steady state. In the benchmark model, though home monetary policy rule can affect foreign households' expected consumption, foreign monetary authority's decision is independent of it. In addition, we know that foreign monetary policy cannot influence home households' expected consumption in the benchmark model. Therefore, foreign monetary responses in Nash case are the same as those in cooperative case. As a comparison, home monetary authority does not take its effects on the expected consumption of foreign households into account when playing Nash game, whereas in cooperative case, the effects must be considered. Thus home monetary responses in Nash case are different from those in 
cooperative case. Inevitably, it leaves room for monetary cooperation. In the extension, when $\frac{1-n}{n}=\frac{1-\varepsilon}{\varepsilon}$, foreign monetary policy has no effects on home households' expected deviation of employment from its steady state. By comparison, home monetary policy affects foreign households' expected deviation of employment from its steady state. However, when $\frac{1-n}{n}=\frac{1-\varepsilon}{\varepsilon}$, the choice of foreign monetary policy rules in cooperative case is identical to that in Nash case, furthermore, it results in a situation in which home monetary responses to shocks in cooperative case are the same as those in Nash case. Consequently, the gains from monetary cooperation disappear.

In the extension, when playing Nash game, both home and foreign monetary authorities can achieve flexibleprice utility levels. In addition, both of them are equal to $-\ln \eta-1$. In DSX (2007), in a Nash equilibrium, home households' welfare is always lower than its foreign counterpart. The reason is that foreign monetary authority can use both the expenditure-level and the expenditure-switching effects, whereas home monetary authority can only take advantage of the expenditure-level effect. In the extension, home monetary authority cannot depend on the expenditure-switching effect both in the upper and lower stages of the production. However, foreign monetary authority can use the expenditure-level and the expenditure-switching effects both in the upper and lower stages of the production. Why can they achieve the same utility level? The reason is that monetary authority is required to deal with the deviation of employment from its steady state rather than the expected consumption. In a model of vertical production and trade with reference currency, when the degree of home bias in consumption is the same as that in production, the global integration of production process requires monetary authorities in both countries to respond effectively to the shocks to the demands for labor thus achieve the utility levels in flexible-price equilibrium which are identical in both countries.

\section{Conclusion}

In this paper, we examine optimal monetary policy rules in a model of vertical production and trade with reference currency. As evidenced by empirical findings, we assume that final- goods prices are sticky, but intermediate-goods prices are flexible. In addition, we assume home bias in both consumption and production. Thus, our model is flexible enough to consider the case of no vertical production and trade.

We find that even if intermediate-goods prices are flexible, monetary authorities need to respond to the shocks at the stage of intermediate-goods production. The reason is that, in our model of vertical production and trade with reference currency, a shock at the home lower stage of the production causes an externality to foreign intermediate-goods producers, foreign monetary authority's monetary response, via vertical production and trade, causes an externality to home final-goods producers as well. Therefore, both monetary authorities need to respond to the shock. We also find that, when a shock occurs at the upper stage of the production, monetary responses are independent of the expenditure share of final-goods producers on intermediate goods.

For the first time in the literature, our model discuss a key problem which is ignored by all researchers, i.e. are the gains from monetary cooperation real or false? In our model, when the covariance between productivity shocks at the two stages is greater than zero, furthermore, if the covariance is greater than a proportion of the variance, then the cooperation is real. Otherwise, it is false.

Does the monetary cooperation result in less volatile nominal exchange rate? We answer the question when the coefficient of relative risk aversion is exactly unity. In general (the expenditure share of households on domestic final goods is not equal to unity), we find that the answer depends on the covariance, variance and the expenditure share of final-goods producers on intermediate-goods.

After vertical production and trade is introduced into an otherwise standard sticky-price model, SX (2007) find that, in PCP case, the nominal exchange rate is more stable. As a comparison, we find that it is not the only answer. The answer depends on the covariance, variance and the expenditure share of final-goods producers on intermediate-goods.

We also extend the model to consider the case of dual price stickiness. In this case, we cannot obtain model's closed-form solution and have to approximate the equilibrium system up to a first order and the welfare function up to a second order. Thus monetary authorities need to focus on the deviation of employment from its steady state not the expected consumption as before. As a result, monetary authorities can achieve the utility levels in flexible-price equilibrium which are identical in both countries. Thus, the gains from monetary cooperation disappear.

\section{Notes}


1 A nonexhaustive list includes: Murphy, Shleifer, and Vishny (1989), Clark (1999), Bils and Klenow (2004), and Nakamura and Steinsson (2008).

2 See OR (2000), Devereux and Engel (2003), DSX (2007), SX (2007), Wang and Zou (2015), Gong, Wang and Zou(2017).

3 See OR (2002), Clarida, Gali, and Gertler (2002), Benigno and Benigno (2003), Pappa (2004), Corsetti and Pesenti (2005), Canzoneri, Cumby, and Diba (2005), Liu and Pappa (2008), and Rabitsch (2012).

4 Here we follow Tille (2001), cross-country substitutability is smaller than within-country substitutability.

5 DSX (2007) consider a more general case in which $\Gamma$ differs from 1.

6 Which is available upon request.

7 Note if there are no other shocks, home and foreign monetary authorities will play a Nash game which results in $S=\theta_{i}^{n(2 \varepsilon-1)}$.

8 In the following, we will not consider the unrealistic cases which involve $n=0$ or $1 ; \varepsilon=0$ or 1 .

9 When $n \neq 1, n<\frac{1}{2-n}$ always holds.

10 The statement can be verified as follows, in Nash case in which there are no other shocks, home representative household's consumption of home final goods is $C_{H}=\Gamma \theta_{f}^{n}$, her consumption of foreign final goos is $C_{F}=\Theta \theta_{f}^{n}$, foreign representative household's consumption of home final goods is $C_{H}^{*}=\Xi \theta_{f}^{n}$, her consumption of foreign final goods is $C_{F}^{*}=$, in which $\Gamma, \Theta, \Xi$, $₹$ are all constant.

11 Note $1-n>\frac{1-n}{2-n}$.

12 In OR (2000), DE (2003), DSX (2007), SX (2007), Wang and Zou (2015), there are no gains from cooperation. As a comparison, there are also evidence to support gains from cooperation, such as OR (2002), Clarida, Gali, and Gertler (2002), Benigno and Benigno (2003), and Pappa (2004), CP (2005), Canzoneri, Cumby, and Diba (2005), Liu and Pappa (2008), and Rabitsch (2012).

13 In this case, international trade in intermediate inputs is shut off and our model returns to DSX (2007) with a slight difference in home bias in consumption.

14 Here we want to emphasize one point, it seems that utility levels without vertical production and trade are almost the same as those with vertical production and trade. The outcome is only a coincidence and follows from our assumption $n=\varepsilon=1 / 2$. For general cases, they are quite different and the conclusion involves complicated comparison. Thus, we leave the general cases as further research.

15 In Proposition 4, we use $\operatorname{var}\left(s^{N}\right)$ to denote the volatility of the nominal exchange rate in Nash case, $\operatorname{var}\left(s^{C}\right)$ in cooperative case. 16 The following analysis does not consider the special case of $n=1$.

17 In Proposition 5, we use $\operatorname{var}\left(s^{V}\right)$ to denote the volatility of the nominal exchange rate when vertical production and trade is present, $\operatorname{var}\left(s^{N V}\right)$ when there is no vertical production and trade. In addition, as SX (2007), we discuss the Nash case.

18 Among many others, see OR (1995, 2001, 2000, and 2002), Betts and Devereux (2000), Sutherland (2002), and Benigno and Benigno (2003), DE (2003), CP (2001 and 2005) DSX (2007), SX (2007), Wang and Zou (2013 and 2015) For an empirical estimate, see Cooley and Hansen (1989).

19 In Proposition 6, we will consider a special case which involves $\frac{1-n}{n}=\frac{1-\varepsilon}{\varepsilon}$, thus it implies that both $n$ and $\varepsilon$ are not equal to zero.

20 In the following, we will only consider the case in which $\frac{1-n}{n}=\frac{1-\varepsilon}{\varepsilon}$.

\section{References}

Benigno, C., and P. Benigno. 2003. "Price Stability in Open Economies.” Review of Economic Studies 70: 743-764.

Betts, C., and M. B. Devereux. 2000. “Exchange Rate Dynamics in a Model of Pricing-to-Market." Journal of International Economics 50: 215244.

Bils, M., and P. J. Klenow. 2004. "Some Evidence on the Importance of Sticky Prices." Journal of Political Economy 112: 947-985.

Bridgman, B. 2012. "The rise of Vertical Specialization Trade." Journal of International Economics 86: 133-140.

Campa, J. M., and L. S. Coldberg. 2005. “Exchange Rate Pass through into Import Prices.” The Review of Economics and Statistics 87: 679-690.

Canzoneri, M. B., R. E. Cumby, and B. T. Diba. 2005. “The Need for International Policy Coordination: what's Old, what's New, what's Yet to Come?" Journal of International Economics 66: 363-384.

Clarida, R., J. Gali, and M. Certler. 2002. “A Simple Framework for International Monetary Policy Analysis.” Journal of Monetary Economics 49 : 879-904.

Clark, T. E. 1999. "The Responses of Prices at Different Stages of Production to Monetary Policy Shocks." The Review of Economics and Statistics 81: $420-433$.

Cooley, T. F., and C. D. Hansen. 1989. “The Inflation Tax in a Real Business Cycle Model." American Economic Review 79 (4): 733-748.

Corsetti, G., and P. Pesenti. 2001. "Welfare and Macroeconomic Interdependence." Quarterly Journal of Economics 116: 421-445.

Corsetti, C., and P. Pesenti. 2005. “International Dimensions of Optimal Monetary Policy.” Journal of Monetary Economics 52: 281-305.

Devereux, M. B., and C. Engel. 2003. "Monetary Policy in the Open Economy Revisited: Price Setting and Exchange Rate Flexibility." Review of Economic Studies 70: 765-783.

Devereux, M. B., and C. Engel. 2007. “Expending Switching Versus Real Exchange Rate Stabilization: Competing Objectives for Exchange Rate Policy." Journal of Monetary Economics 54: 2346-2374.

Devereux, M. B., K. Shi, and J. Xu. 2007. “Global Monetary Policy Under a Dollar Standard.” Journal of International Economics 71: 113-132.

Feenstra, Robert C. 1998. "Integration of Trade and Disintegration of Production in the Clobal Economy." Journal of Economics Perspectives 12: 31-50.

Feldstein, M. 1992. "The Case Against EMU." The Economist 19-22.

Friedman, M. 1953. The Case for Flexible Exchange Rates, in Essays in Positive Economics. Chicago: Chicago University Press.

Coldberg, L., and C. Tille. 2008. "Vehicle Currency Use in International Trade." Journal of International Economics 76: 177-192.

Coldberg, L., and C. Tille. 2009. "Macroeconomic Interdependence and the International Role of the Dollar." Journal of Monetary Economics 56: 990-1003.

Cong, Liutang, Chan Wang, and Heng-fu Zou. 2017 (2) 14. “Optimal Exchange-Rate Policy in a Model of Local-Currency Pricing with Vertical Production and Trade." Open Economies Review 28 (1): 125-147.10.1007/s11079-016-9415-y.

Copinath, G., O. Itskhoki, and R. Rigobon. 2010. “Currency Choice and Exchange Rate Pass-Through.” American Economic Review 100 (1): $304-$ 336. 
Hummels, D., I. Jun, and Kei-Mu Yi. 2001. "The Nature and Growth of Vertical Specialization in World Trade." Journal of International Economics 54: 75-96.

Hummels, D., R. Dana, and Kei-Mu Yi. 1998. “Vertical Specialization and the Changing Nature of World Trade.” Economic Policy Review 4: 7999.

Liu, Z., and E. Pappa. 2008. Gains from International Monetary Policy Coordination: Does it Pay to be Different?" Journal of Economic Dynamics and Control 32: 2085-2117.

Mundell, Robert. 1961. “A Theory of Optimum Currency Areas.” American Economic Review 51: 657-665.

Murphy, K. M., A. Shleifer, and R. W. Vishny. 1989. "Building Blocks of Market Clearing Business Cycle Models." NBER Macroeconomics Annual 4: 247-287.

Nakamura, E., and ]. Steinsson. 2008. “Five Facts about Prices: a Reevaluation of Menu Cost Models." The Quarterly Journal of Economics 123: $1415-1464$.

Obstfeld, M., and K. Rogoff. 1995. “Exchange Rate Dynamics Redux.” Journal of Political Economy 103: 624-660.

Obstfeld, M., and K. Rogoff. 2001. "Risk and Exchange Rates." Prepared for the conference in honor of Assaf Razin.

Obstfeld, M., and K. Rogoff. 2000. "New Directions for Stochastic Open Economy Models." Journal of International Economics 50: 117-153.

Obstfeld, M., and K. Rogoff. 2002. “Clobal Implications of Self-Oriented National Monetary Rules.” Quarterly Journal of Economics 117: 503535 .

Pappa, E. 2004. "Do the ECB and the Fed Really Need to Cooperate? Optimal Monetary Policy in a Two-Country World." Journal of Monetary Economics 51: 753-779.

Rabitsch, K. 2012. "The Role of Financial Market Structure and the Trade Elasticity for Monetary Policy in Open Economies." Journal of Money, Credit and Banking 44: 603-629.

Shi, K., and J. Y. Xu. 2007. “Optimal Monetary Policy with Vertical Production and Trade.” Review of International Economics 15 (3): $514-537$.

Shi, K., and J. Y. Xu. 2010. “Twin Dollarization and Exchange Rate Policy." Journal of International Economics 81: 109-121.

Sutherland, A. 2002. "International Monetary Policy Coordination and Financial Market Integration." ECB Working Paper No. 174.

Tille, C. 2001. "The Role of Consumption Substitutability in the International Transmission of Monetary Shocks." Journal of International Economics 53: 421-444.

Wang, C., and H. F. Zou. 2013. "On the Efficiency of Monetary and Fiscal Policy in Open Economies." Annals of Economics and Finance 14: 179206.

Wang, C., and H. F. Zou. 2015. “Optimal Monetary Policy Under a Clobal Dollar Standard: the Effect of Vertical Trade and Production.” Open Economies Review 126: 121-137.

Yi, K.-M. 2003. “Can vertical Specialization Explain the Growth of World Trade?” Journal of Political Economy 111: 52-102.

Yi, K.-M. 2010. “Can Multistage Production Explain the Home Bias in Trade?” American Economic Review 100 (1): 364-393. 